\title{
A Battleground with no Neutral Ground: Twitter for Scientists
}

\author{
C Beavers ${ }^{1}$ \\ ${ }^{1}$ Diamond Light Source, Didcot \\ Christine.Beavers@diamond.ac.uk
}

The world is simultaneously terrifying and electrifying right now; social media is high-fidelity reflection of this, misinformation and all. Twitter offers a platform to the voiceless and disenfranchised as well as the loud and powerful. As scientists, we are privileged to have other platforms available to us for voicing our thoughts, opinions and research; due to this, we are used to placing our thoughts into a context. The reality of social media is that we cannot chose the context that our posts exist within. Understanding and reacting to the zeitgeist are key skills needed for effective navigation of the social media landscape. There are times to post and there are times to listen and amplify; this presentation will explore trending topics and appropriate responses relevant to the crystallographic community.

Acta Cryst. (2020). A76, a127 